\title{
Características metodológicas utilizadas nos estudos de impacto econômico em saúde com enfoque em câncer de próstata: uma revisão sistemática
}

\author{
Júlio Augusto de Lima PASSONE ${ }^{(1)}$ \\ Lúcia Dias da Silva GUERRA ${ }^{(1)}$ \\ ${ }^{(1)}$ Faculdade de Saúde Pública, Universidade de São Paulo - USP, São Paulo, SP, Brasil.
}

\section{Resumo}

A carga da doença é um conceito que envolve mortalidade e perda de saúde devido à doenças, lesões e fatores de risco para todas regiões do mundo. Apesar de serem medidas fundamentais na elaboração de políticas públicas, fornecem uma visão parcial do estado da saúde pública. A carga econômica da doença, por sua vez, abrange custos financeiros das doenças para indivíduos, lares, sistema de saúde e sociedades. O aumento dos gastos pessoais com saúde, redução da capacidade funcional e perda de renda ou produtividade são considerados fatores de risco primários para o empobrecimento da população. Da mesma forma, condições de saúde precárias também podem afetar o nível educacional da população. No âmbito social, a saúde da população está diretamente relacionada às taxas de poupança, retorno sobre o capital e níveis de investimento interno e externo, sendo esses fatores impactantes no crescimento

Recebido: 28 jan 2019 Aceito: 10 fev 2019

Autor de correspondência: julio.passone@gmail.com

Conflito de interesses: Os autores declaram não haver nenhum interesse profissional ou pessoal que possa gerar conflito de interesses em relação a este manuscrito. econômico. Assim, é possível mensurar até que ponto uma doença específica ou, de forma mais geral, um estado de saúde interrompe ou reduz as oportunidades econômicas de produção ou consumo a nível familiar ou social. No caso, das doenças crônicas não transmissíveis, como o câncer, verifica-se que é crescente o número de pessoas vivas com históricos de câncer no mundo. Espera-se que a prevalência de sobrevivência ao câncer seja ainda maior no futuro, considerando o crescimento e envelhecimento da população, além do aumento da sobrevida após o diagnóstico gerado pelos avanços na triagem, detecção e tratamento. $O$ câncer de próstata está entre as cinco neoplasias com maior incidência e mortalidade, além de ser mundialmente a principal causa de morte entre os homens. A cada ano são diagnosticados 1,6 milhões de novos pacientes e registradas aproximadamente 366.00 mortes. Apesar disso, a sobrevida desses pacientes está crescendo nos últimos anos principalmente devido aos avanços terapêuticos e a detecção precoce da doença. O número de estudos de impacto econômico na saúde cresceu exponencialmente desde a adoção do termo custo da doença (tradução do inglês, cost-of-illness) em meados da década de 1960. Embora a maioria dos estudos continue a utilizar alguma variante desta metodologia, como a combinação de custos diretos e indiretos, os modelos de crescimento macroeconômico têm sido cada vez mais utilizados para a compreensão da natureza dinâmica e multifacetada das perdas no nível social, com a finalidade de utilização em políticas e pesquisas para entender melhor as 
consequências microeconômicas da doença, particularmente no nível doméstico em países de baixa renda. Objetivo: avaliar as características metodológicas utilizadas nos estudos de impacto econômico em saúde, com enfoque em câncer de próstata, através de revisão sistemática da literatura. Métodos: uma revisão sistemática será realizada para identificação de estudos de custo da doença, estudos observacionais e estudos qualitativos que têm como objetivo a coleta de custos e determinação do impacto econômico em saúde. A busca abrangerá bases de dados da campo da saúde e das ciências humanas, como: MEDLINE (PubMed), Embase, Literatura Latino-Americana e do Caribe em Ciências da Saúde - LILACS, Scientific Electronic Library Online - SciELO; repositórios de avaliações econômicas: The Centre for Reviews and Dissemination - CRD: NHS Economic Evaluation Database NHS EED, Database of Abstracts of Reviews of Effects DARE; Health Technology Assessment Database HTA e literatura cinzenta em sites de Agências Regulatórias e de Avaliação de Tecnologias em Saúde - ATS mundiais. Se necessário, também será realizada busca manual de referências utilizadas nos estudos selecionados. Não haverá restrição por língua ou data. Os estudos identificados serão gerenciados através do software Mendeley, que auxiliará na remoção das duplicatas através da análise do título, autores, instituição, Digital Object Identifier - DOI, palavras-chave e língua. Após remoção das duplicatas, será realizada leitura dos títulos e resumos para seleção dos artigos de acordo com os critérios de inclusão e exclusão pré-estabelecidos. Por fim, a leitura completa dos artigos selecionados será feita para identificação final dos estudos que serão validados. Para estratégia de busca utilizou-se os termos indexadores de cada base e operadores de busca, considerando dois blocos: custo da doença/carga econômica da doença e câncer de próstata. A extração de dados considerará o desenho do estudo; informações descritivas sobre a população em geral; nível domiciliar ou individual; delineamento da pesquisa; tamanho da amostra; período do estudo; cenário; objetivos e especificações do grupo de controle; dimensão do impacto socioeconômico (despesas relacionadas com a saúde, despesas não relacionadas com a saúde, emprego, responsabilidades das famílias, proteção social, segurança alimentar, outras); detalhes da patologia (tipo, estágio da doença); fonte de dados - bases de dados nacionais, inquéritos longitudinais, inquéritos transversais, estudos de casos); panorama da análise do impacto econômico em saúde; metodologia utilizada; finalidade; principais conclusões e resultados. Considerações finais: estima-se que a utilização de serviços de saúde e aumento dos custos do tratamento do câncer devam resultar em uma carga maior de câncer no futuro. No âmbito da oncologia, projetar e estimar a carga econômica do câncer, incluindo gastos com saúde, perda de produtividade e morbidade para os pacientes e suas famílias, são questões cada vez mais importantes para pesquisadores, gestores e formuladores de políticas de saúde, bem como profissionais da saúde e sociedade.

Descritores: Neoplasias de Próstata; Efeitos Psicossociais da Doença; Saúde Pública. 